\title{
Urgences
}

\section{Rocaille : octobre (version préliminaire)}

\section{Michel Gay}

Numéro 16, mars 1987

D.G. Jones : d'un texte, d'autres

URI : https://id.erudit.org/iderudit/025386ar

DOI : https://doi.org/10.7202/025386ar

Aller au sommaire du numéro

Éditeur(s)

Urgences

ISSN

0226-9554 (imprimé)

1927-3924 (numérique)

Découvrir la revue

Citer ce document

Gay, M. (1987). Rocaille : octobre (version préliminaire). Urgences, (16), 46-47. https://doi.org/10.7202/025386ar

Ce document est protégé par la loi sur le droit d'auteur. L’utilisation des services d’Érudit (y compris la reproduction) est assujettie à sa politique d'utilisation que vous pouvez consulter en ligne.

https://apropos.erudit.org/fr/usagers/politique-dutilisation/
Cet article est diffusé et préservé par Érudit.

Érudit est un consortium interuniversitaire sans but lucratif composé de l’Université de Montréal, l’Université Laval et l’Université du Québec à Montréal. Il a pour mission la promotion et la valorisation de la recherche. https://www.erudit.org/fr/ 


\section{Michel Gay \\ ROCAILLE: OCTOBRE (version préliminaire)}

Dans la bruine, c'est une ruine d'ombres, c'est

la tombe des fleurs

Ici sont réunies les couleurs des feuilles mortes. Encore que ce sont les pierres qui fleurissent

comme une réunion de tomes où ceux qui sont partis parlent encore

De plus en plus ma bouche s'emplit de pierres

et les os de mes collègues

ont l'air de fleurs

Est-ce, le fouillis, le paradis ou Angkor Wat

ou la cité intérieure après

10 h? Ce n'est ni

vivant ni mort

ni humain. Je l'aperçois

dans la bruine, tênébreux. C'est un rayon de runes 
Lettre de Joseph Bonenfant. Projet de numéro de la revue Urgences. Poème de D.G. Jones. Rock Garden: October. Traduire. Tombée: 30 janvier. Date «impérative», selon le mot de Bonenfant. Impossible, bien sûr, à "respecter": tombée, traduction, poème de Jones. Tous les problèmes que soulève la traduction; en général, en particulier. Travail préliminaire: lire, relire - inlassablement? - le poème de Jones. Ce que ça «dit», ce que ça «écrit», et comment. La construction du texte: strophes, ponctuation, vocabulaire, syntaxe, figures... Telle ligne, par exemple: «or Angkor Wat» $\rightarrow$ «ou encore quoi», oui (voir l'angrais Duchamp de Gervais - André; et pour ce qui concerne le Rock Garden de Jones, ou plus simplement le regardant, ceci: "Ce qui fut mis «fumier» est "en fleurs"» [la Raie alitée d'effets, p. 287]). Première version (donc) où sont ouvertes quelques pistes. Par exemple: «bruine/ruine», ce "rain/ruin" qui est venu, d'abord, de "pluie/ruine», puis de "pluie/débris» («bruine» levée, élevée sans doute sur ces "débris de pluie» - première inversion en cette version préliminaire). Par exemple: "gone go on / talking» devenu "partis parlent/encore», après le littéral «partis continuent/ de parler» deuxième inversion et introduction du leitmotiv «encore»; d'où retour au cinquième vers pour option «encore que» / "still». "Angkor Wat", oui. Par exemple: le difficile "growth of runes", laissé en plan, puis, pour le moment, en ce jeu (plus ou moins malhabile) de mots: «rayon de runes». Continuer ainsi d'approcher le poème de Jones, mot à mot. Plus tard, quand le travail sera plus avancé (sic), s'il le devient (resic), assurer, dans l'autre langue (qui est celle-ci), un minimum de cohérence; d'où, éventuellement, un minimum d'adhérence - d'un texte (à) l'autre. Va. 